\title{
Anti-platelet activity of panaxatriol saponins is mediated by suppression of intracellular calcium mobilization and ERK2/p38 activation
}

Hongyi Qi ${ }^{1+}$, Yongliang Huang ${ }^{2+}$, Yi Yang ${ }^{1}$, Guojun Dou' ${ }^{1}$ Fang Wan ${ }^{3}$, Wenwu Zhang ${ }^{3}$, Huarong Yang ${ }^{3}$, Li Wang ${ }^{3}$, Chunjie $\mathrm{Wu}^{4}$ and $\mathrm{Li} \mathrm{Li}^{\mathrm{i}^{*}}$

\begin{abstract}
Background: Increased platelet aggregation is implicated in the pathogenesis of ischemic stroke and anti-platelet strategy may contribute to its therapy. Panaxatriol saponin (PTS), the main components extracted from Panax notoginseng, has been shown to be efficacious in the prevention and treatment of ischemic stroke in China. The aim of this study is to determine the anti-platelet activity and explore the underlying mechanisms.

Methods: Inhibitory effect of PTS and its main ginsenosides on agonists-induced platelet aggregation was determined using rabbit or human platelets. Intracellular $\mathrm{Ca}^{2+}$ concentration $\left(\left[\mathrm{Ca}^{2+}\right]\right.$ ) mobilization was detected with fura-2/AM probe. MAPKs phosphorylation was determined by Western blotting.

Results: Our results showed PTS inhibited the rabbit platelet aggregation induced by various agonists (collagen, thrombin and ADP). The three main ginsenosides (Rg1, Re and R1) existing in PTS also showed anti-platelet activity, while their combination exhibited no synergistic effect on rabbit platelet aggregation. Further study demonstrated that PTS and its main ginsenosides also exhibited inhibitory effect on human platelet aggregation. Mechanism study demonstrated that pre-treatment with PTS inhibited the agonists-induced intracellular calcium mobilization. Moreover, PTS significantly suppressed the activation of both ERK2 and p38 by the agonists via reducing the phosphorylation of ERK2 and p38.

Conclusion: We proved that PTS is effective in anti-platelet aggregation, which may, at least in part, be related to the suppression of intracellular calcium mobilization and ERK2/p38 activation. This study may provide one reasonable explanation for the efficacy of PTS on the prevention and treatment of ischemic stroke.
\end{abstract}

Keywords: Panaxatriol saponin, Platelet aggregation, Intracellular calcium mobilization, p-ERK2, p-p38

\section{Background}

Platelets which only exist in mammals mainly function as stopping bleeding at the site of interrupted endothelium. Under normal physiological condition, platelets are quiescent and don't bind to fibrinogen. Once there is an injury in the endothelium, platelets will adhere to the interrupted endothelium and become activated via changing

\footnotetext{
* Correspondence: lilyli029@126.com

${ }^{\dagger}$ Equal contributors

${ }^{1}$ College of Pharmaceutical Sciences, Southwest University, 2 Tiansheng

Road, Beibei District, Chongqing 400716, China

Full list of author information is available at the end of the article
}

shape, turning on receptors and secreting chemical messengers. Then, they interconnect through receptor bridges to form aggregation and finally promote the blood coagulation [1]. However, abnormal platelet activation triggered by pathophysiological factors can lead to the development and progression of vascular diseases [2]. Increased platelet aggregation is believed to play an important role in the pathogenesis of ischemic stroke [3]. Therefore, anti-platelet therapy may represent an alternative way for the prevention and treatment of ischemic stroke.

\section{() Biomed Central}

(c) 2016 The Author(s). Open Access This article is distributed under the terms of the Creative Commons Attribution 4.0 International License (http://creativecommons.org/licenses/by/4.0/, which permits unrestricted use, distribution, and reproduction in any medium, provided you give appropriate credit to the original author(s) and the source, provide a link to the Creative Commons license, and indicate if changes were made. The Creative Commons Public Domain Dedication waiver (http://creativecommons.org/publicdomain/zero/1.0/) applies to the data made available in this article, unless otherwise stated. 
Panaxatriol saponin (PTS) is one of the major components of Panax notoginseng and composed of ginsenoside Rg1 (Rg1), notoginsenoside R1 (R1) and ginsenoside $\operatorname{Re}(\mathrm{Re})$. It has been clinically used in China for the treatment of cerebral infarction. Previous pharmacological study demonstrated that PTS alleviated the focal cerebral ischemia-induced injury via reducing the cerebral edema, up-regulating HSP70 expression and down-regulating transferring [4]. Our recent investigation indicated that PTS exerted neuroprotection through modulating the cyto-protective Nrf2 signaling pathway [5]. In addition, several studies have reported that ginsenosides, for example, Rp1 [6], Rg3 [7], Rg1 [8], Rh1 and F1 [9], exhibited the anti-platelet activities. In view of the protective effect on ischemic stroke, whether PTS also has the anti-platelet activity is accordingly drawing our attention. Therefore, we designed experiments to investigate the effect of PTS on platelet aggregation and explore the underlying mechanisms in the current study.

\section{Methods \\ Materials}

PTS extracted from Panax notoginseng was obtained from Huasun Group Co., Ltd. (Sichuan, China). As determined in our previous study [5], PTS is comprised of Rg1, R1 and Re with the concentration of $46.1,12.3$ and $5.7 \%$, respectively. The antibodies against p-ERK, p-p38 and HRP conjugated goat anti-mouse IgG were purchased from Cell Signaling Technology (Boston, MA, USA). Thrombin and collagen were purchased from Sigma-Aldrich (St. Louis, MO, USA). ADP was obtained from Tokyo Chemical Industry (Shanghai) Co. Ltd. (Shanghai, China). Fura-2/ AM was obtained from Beyotime Biotechnology Corporation (Jiangsu China). Other chemicals were obtained from Sigma-Aldrich Co. (St. Louis, MO, USA) unless indicated otherwise. Human peripheral blood was collected from healthy human donors after obtaining the informed consent under a Chengdu University of Traditional Chinese Medicine Internal Review Board-approved protocol.

\section{Experimental animals}

New Zealand albino rabbits $(2.0 \pm 0.2 \mathrm{~kg})$ used in this study were obtained from Experimental Animal Center of Chengdu University of Traditional Chinese Medicine. The animals were acclimated for 1 week prior to the experiments, and housed in an air-conditioned animal room with a $12 / 12 \mathrm{~h}$ light/dark cycle at a temperature of $25 \pm 1{ }^{\circ} \mathrm{C}$ and humidity of $50 \pm 10 \%$. The animals were provided with a laboratory diet and water ad libitum. All experimental protocols involving the use of animals were conducted in accordance with National Institutes of Health (NIH) guidelines and approved by the Committee on Animal Care at the Southwest University.

\section{Platelet preparation}

The preparation of the platelets has been described previously with minor modifications [6]. The human blood or rabbit blood was transferred to a tube containing $1 \mathrm{ml}$ of a citrate phosphate dextrose solution $(90 \mathrm{mM}$ $\mathrm{Na}_{3} \mathrm{C}_{6} \mathrm{H}_{5} \mathrm{O}_{7} \cdot 2 \mathrm{H}_{2} \mathrm{O}, 16 \mathrm{mM} \quad \mathrm{C}_{6} \mathrm{H}_{8} \mathrm{O}_{7} \cdot \mathrm{H}_{2} \mathrm{O}, 16 \mathrm{mM}$ $\mathrm{NaH}_{2} \mathrm{PO}_{4} \cdot \mathrm{H}_{2} \mathrm{O}, 142 \mathrm{mM}$ dextrose). Platelet-rich plasma (PRP) was obtained by centrifuging rabbit blood samples at $230 \times \mathrm{g}$ for $5 \mathrm{~min}$. Platelets were precipitated by centrifugation of the PRP at $800 \times \mathrm{g}$ for $15 \mathrm{~min}$ and washed twice with the washing buffer $\left(10 \mathrm{mM} \mathrm{Na} \mathrm{C}_{6} \mathrm{H}_{5} \mathrm{O}_{7}\right.$. $2 \mathrm{H}_{2} \mathrm{O}, 150 \mathrm{mM} \mathrm{NaCl}, 1 \mathrm{mM}$ EDTA,1 \% (w/v) dextrose and $\mathrm{pH}$ 7.4). The pellet was re-suspended in HEPES buffer (140 mM NaCl, $2.7 \mathrm{mM} \mathrm{KCl,} 3.8 \mathrm{mM}$ HEPES, $5 \mathrm{mM}$ EGTA and $\mathrm{pH}$ 7.4) and the cell dilution was adjusted to $4 \times 10^{8}$ cells $\cdot \mathrm{ml}^{-1}$ for subsequent experiment.

\section{Platelet aggregation assay}

Platelet aggregation was performed as previously described [10]. Briefly, blank solvent and test samples at various concentrations were added to $200 \mu \mathrm{l}$ of PRP and after 15 min aggregation was initiated by adding different inducers in each well of 96-well plates, respectively. Optical density (OD) at $630 \mathrm{~nm}$ was measured with Microplate Reader (BioTek ELX800) after 1, 2, 4, $10 \mathrm{~min}$ of the addition. All the experiments were performed in triplicate. The platelet aggregation rate is expressed as PAR (\%) and calculated as follows:

$$
\operatorname{PAR}(\%)=\left(1-\mathrm{OD}_{0}\right) / \mathrm{OD}_{1} \times 100 \%
$$

Whereas $\mathrm{OD}_{0}$ and $\mathrm{OD}_{1}$ indicate the optical density before and after the inducer is added, respectively.

The following equation is used to calculate the inhibition rate (IR) of platelet aggregation.

$$
\operatorname{IR}(\%)=\left(1-\mathrm{PAR}_{\text {test }}\right) / \mathrm{PAR}_{\text {blank }} \times 100 \%
$$

Whereas PAR $_{\text {test }}$ and PAR $_{\text {blank }}$ represent the PAR of the tested samples and the blank solvent, respectively.

\section{Determination of the intracellular calcium concentration $\left(\left[\mathrm{Ca}^{2+}\right]_{\mathrm{i}}\right)$} $\left[\mathrm{Ca}^{2+}\right]_{i}$ was determined with fura-2/AM as described previously [6]. Briefly, the PRP with concentration of $4 \times 10^{8}$ cells $/ \mathrm{ml}$ was incubated with $5 \mu \mathrm{M}$ of fura-2/AM for $60 \mathrm{~min}$ at $37^{\circ} \mathrm{C}$. The fura-2-loaded washed platelets were pre-incubated with the tested sample or the blank solvent (saline) for $3 \mathrm{~min}$ at $37{ }^{\circ} \mathrm{C}$ in the presence of $1 \mathrm{mM} \mathrm{CaCl}_{2}$. Next, the platelets were stimulated with thrombin $\left(0.1 \mathrm{U} \cdot \mathrm{ml}^{-1}\right)$, collagen $\left(2.5 \mu \mathrm{g} \cdot \mathrm{ml}^{-1}\right)$ or ADP $(10 \mu \mathrm{M})$ for $5 \mathrm{~min}$, respectively. Fura-2 fluorescence was measured in a spectrofluorometer (F-2500, Hitachi, Japan) with an excitation wavelength of $340 \mathrm{~nm}$ and an emission wavelength of $510 \mathrm{~nm}$. The $\left[\mathrm{Ca}^{2+}\right]_{i}$ was 
calculated by the method of Schaeffer [11]: $\left[\mathrm{Ca}^{2+}\right]_{i}$ in cytosol $=224 \mathrm{nM} \times\left(F-F_{\text {min }}\right) /\left(F_{\text {max }}-F\right)$, where $224 \mathrm{nM}$ is the dissociation constant of the fura-2- $\mathrm{Ca}^{2+}$ complex, and $F_{\min }$ and $F_{\text {max }}$ represent the fluorescence intensity levels at very low and very high $\mathrm{Ca}^{2+}$ concentrations, respectively. In our experiment, $F_{\max }$ is the fluorescence intensity of the fura-2- $\mathrm{Ca}^{2+}$ complex at $510 \mathrm{~nm}$ after the platelet suspension containing $1 \mathrm{mM}$ of $\mathrm{CaCl}_{2}$ had been solubilized by Triton X-100 (0.1\%). $F_{\min }$ is the fluorescence intensity of the fura-2- $\mathrm{Ca}^{2+}$ complex at $510 \mathrm{~nm}$, after the platelet suspension containing $20 \mathrm{mM}$ Tris/ $3 \mathrm{mM}$ of EGTA had been solubilized by Triton X-100 $(0.1 \%) . F$ represents the fluorescence intensity of the fura-2-complex at $510 \mathrm{~nm}$ after the platelet suspension was stimulated by inducer, with and without the tested samples, in the presence of $1 \mathrm{mM} \mathrm{CaCl} 2$.

\section{Western blotting analysis}

The cellular proteins were extracted and analyzed for protein expression as previously described [12]. Briefly, thirty micrograms of the cellular proteins were resolved by electrophoresis in $10 \%$ SDS-polyacrylamide gel, and subsequently transferred to polyvinylidene difluoride (PVDF) membrane. Following $1 \mathrm{~h}$ incubation in a fresh TBS buffer containing $0.1 \%$ Tween-20 and $5 \%$ BSA, the blots were probed with specific antibodies including anti-p-ERK, anti-p-p38 and anti- $\beta$-actin. The bound primary antibodies were detected by HRP conjugated antimouse IgG accordingly. The activity of peroxidase on the blot was visualized by enhanced chemiluminescence (ECL) detection reagents (GE Healthcare, Sweden).

\section{Statistical analysis}

All data were presented as mean \pm SD from three independent experiments. Statistical analysis was performed by two-tail Student's $t$-test. A $P$-value of less than 0.05 was considered to be statistically significant.

\section{Results}

Inhibitory effect of PTS on agonist induced rabbit platelet aggregation

To determine the effect of PTS on rabbit platelet aggregation, we examined its anti-platelet activity against stimulation of different agonists. washed platelets were pre-incubated with different concentrations of PTS and then exposed to collagen, thrombin and ADP, respectively. As shown in Fig. 1a, PTS significantly inhibited the rabbit platelet aggregation activated by collagen at the concentration of 1,3 and $10 \mathrm{mg} \cdot \mathrm{ml}^{-1}$, with the inhibition rate of 63.9, 69.8 and $71.3 \%$, respectively. Figure $1 \mathrm{~b}$ shows that treatment of rabbit platelets with 3 and $10 \mathrm{mg} \cdot \mathrm{ml}^{-1}$ PTS markedly inhibited the aggregation induced by thrombin, with the inhibition rate of 55.5 and $56.4 \%$, respectively. Similarly, 3 and $10 \mathrm{mg} \cdot \mathrm{ml}^{-1}$ PTS also significantly inhibited
ADP-induced rabbit platelet aggregation with the inhibition rate of 55.3 and $55.9 \%$, respectively.

\section{Inhibitory effect of the main ginsenosides in PTS on thrombin induced rabbit platelet aggregation}

As PTS consists of three main ginsenosides ( $\operatorname{Rg} 1, \operatorname{Re}$ and $\mathrm{R} 1$ ), we are then interested in the effect of these single compounds on rabbit platelet inhibition and asked whether there is a synergistic effect when they are used as a combination. As shown in Fig. 2a, Rg1 dose-dependently inhibited the aggregation activated by thrombin within the concentration of 10-100 $\mu \mathrm{M}$. However, both Re and R1 only significantly inhibited the thrombin induced rabbit platelet aggregation at $100 \mu \mathrm{M}$ within the same tested concentration range (Fig. $2 \mathrm{~b}$ and c). When these three compounds were used together at the same concentration, only the combination with 50 and $100 \mu \mathrm{M}$ showed significantly inhibitory activity on thrombin induced rabbit platelet aggregation and there was no synergistic effect observed.

\section{Inhibitory effect of PTS and its main ginsenosides on agonist induced human platelet aggregation}

To further confirm the anti-platelet aggregation effect of PTS and its main ginsenosides, we then determined their inhibitory effect on human platelet aggregation. As shown in Fig.3a, PTS significantly inhibited the human platelet aggregation induced by collagen, thrombin and ADP, respectively. Moreover, the three main ginsenosides (Rg1, Re and R1) also exhibited significant antiplatelet aggregation effect against ADP-induced human platelet aggregation (Fig.3b).

\section{Effect of PTS on calcium mobilization}

It's well established that $\left[\mathrm{Ca}^{2+}\right]_{i}$ is critical for the activation and aggregation of platelet aggregation [13-15]. The decrease of $\left[\mathrm{Ca}^{2+}\right]_{i}$ directly inhibits the platelet aggregation. Therefore, we determined the influence of PTS on the calcium mobilization. Figure 4a showed that thrombin alone markedly enhanced the $\left[\mathrm{Ca}^{2+}\right]_{i}$. When pre-incubation of platelets with various concentration of PTS, the $\left[\mathrm{Ca}^{2+}\right]_{i}$ induced by thrombin dose-dependently decreased by $58.2,67.3$ and $79.4 \%$ at concentrations of $0.5,1$ and $3 \mathrm{mg} \cdot \mathrm{ml}^{-1}(p<0.05)$, respectively. Similarly, Fig. $4 \mathrm{~b}$ and $\mathrm{c}$ show that 1 and $3 \mathrm{mg} \cdot \mathrm{ml}^{-1}$ of PTS significantly reduced collagen-activated $\left[\mathrm{Ca}^{2+}\right]_{i}$ and $3 \mathrm{mg} \cdot \mathrm{ml}^{-1}$ of PTS significantly reduced ADP-activated $\left[\mathrm{Ca}^{2+}\right]_{i}$.

\section{Effect of PTS on the phosphorylation of MAPKs}

Since MAPKs (ERK2, JNK1 and p38) are reported to be present in platelets and involved in the action of numerous anti-platelet agents [16], we determined whether thrombin induced MAPKs phosphorylation is regulated as a signaling pathway in the anti-platelet activity of PTS. As 


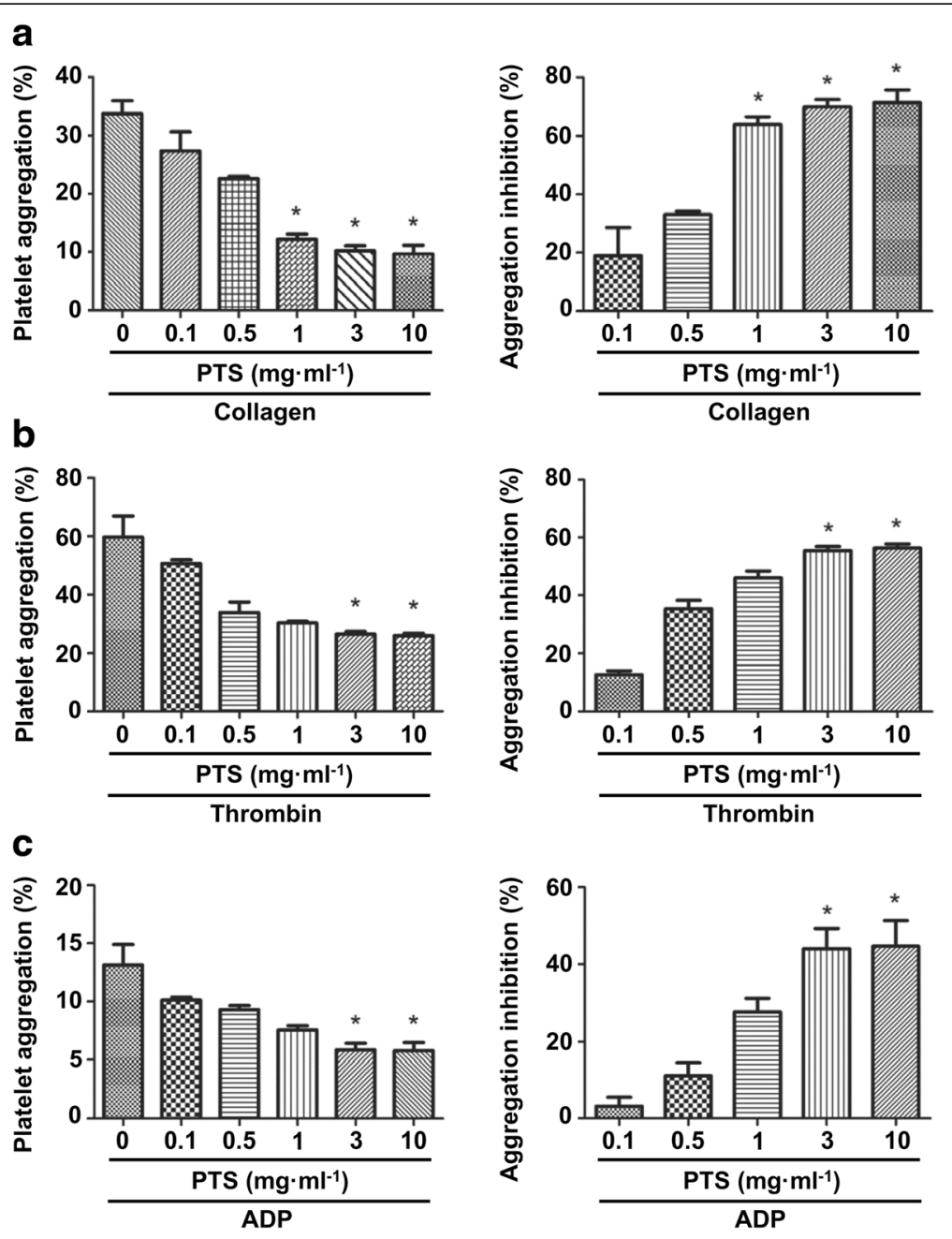

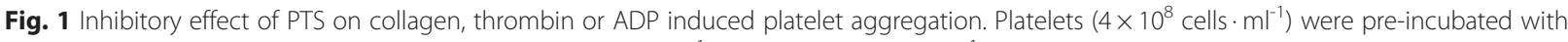
or without PTS and then stimulated with $\mathbf{a}$ collagen $\left(2.5 \mu \mathrm{g} \cdot \mathrm{ml}^{-1}\right), \mathbf{b}$ thrombin $\left(0.1 \mathrm{U} \cdot \mathrm{ml}^{-1}\right)$ or $\mathbf{c}$ ADP $(10 \mu \mathrm{M})$. The platelet aggregation rate and the inhibition rate of platelet aggregation were determined. Bar graphs show mean \pm SD of at least 3 independent experiments performed. ${ }^{*} p<0.05$ vs. agonist activated control

shown in Fig. 5a, PTS with 1 and $3 \mathrm{mg} \cdot \mathrm{ml}^{-1}$ significantly reduced the phosphorylation of ERK2 induced by thrombin. Meanwhile, PTS with the concentrations of $0.5-3 \mathrm{mg} \cdot \mathrm{ml}^{-1}$ significantly reduced the phosphorylation of p38 induced by thrombin (Fig. 5b). Then, we further determined the effect of PTS on the phosphorylation of ERK2 and p38 induced by collagen and ADP, respectively. Figure $5 \mathrm{c}$ and e show that the phosphorylation of ERK2 induced by collagen and ADP was significantly reduced by PTS and Fig. $5 \mathrm{~d}$ and $\mathrm{f}$ show that the phosphorylation of p38 induced by collagen and ADP was also significantly reduced by PTS.

\section{Discussion}

In this study, we first determined the inhibitory activity of PTS on platelet aggregation activated by collagen, thrombin and ADP, respectively. It's well established that the three different agonists act on different types of receptors. Collagen is a potent ligand against integrin-type receptors, including $\alpha 2 \beta 1$ and glycoprotein VI, whereas thrombin and ADP are potent ligands of G-protein coupled seven transmembrane receptors (GPCR) (PAR-1 and PAR- 4 thrombin receptors, $\mathrm{P}_{2} \mathrm{Y}_{1}$ and $\mathrm{P}_{2} \mathrm{Y}_{12}$ ADP receptors), respectively [17-19]. Our result demonstrated that PTS showed anti-platelet activity irrelevant to the types of agonists, suggesting that PTS may not function as an antagonist to counteract the binding to platelet receptors on the plasma membrane of these three agonists. PTS is a complex fraction containing three major ginsenosides Rg1, Re and R1 [5]. Previous study showed that Rg1 [8] exhibited anti-platelet activity. Then, we are interested to determining the effect of another two main 

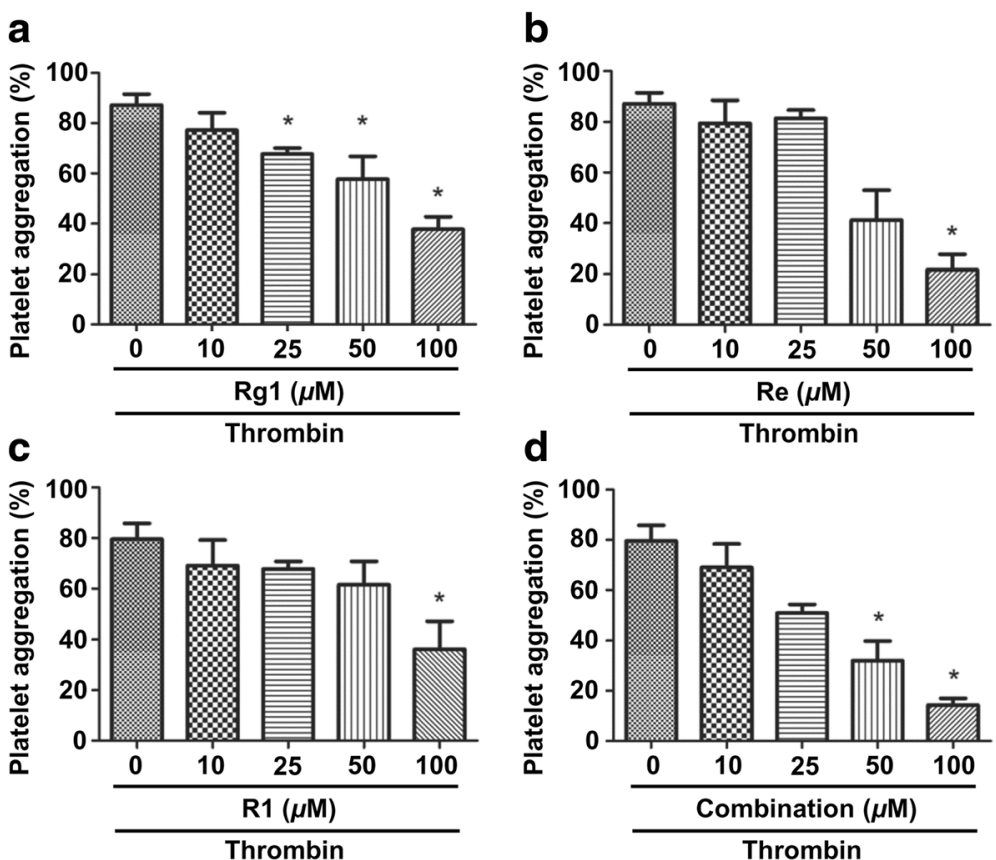

Fig. 2 Inhibitory effect of the main ginsenosides in PTS on thrombin induced platelet aggregation. Platelets $\left(4 \times 10^{8}\right.$ cells $\left.\cdot \mathrm{ml}^{-1}\right)$ were pre-incubated with or without $\operatorname{Rg} 1(\mathbf{a}), \operatorname{Re}(\mathbf{b}), \operatorname{R} 1(\mathbf{c})$ or their combination of equal concentration $(\mathbf{d})$, and then stimulated with thrombin $\left(0.1 \mathrm{U} \cdot \mathrm{ml}^{-1}\right)$. The platelet aggregation rate was determined. Bar graphs show mean \pm SD of at least 3 independent experiments performed. ${ }^{*} p<0.05$ vs. agonist activated control

compounds (Re and R1) in PTS on platelet aggregation and whether the combination of these three ginsenosides could function synergistically. As a result, Rg1 inhibited the platelet aggregation at relative low concentrations, whereas Re showed stronger effect at higher concentration. The inhibitory activity of R1 was much similar than that of Re. However, the potency of the combination in inhibiting platelet aggregation didn't improve, indicating there may be no synergistic effect among the components in PTS. To make our study become more clinical relevance, we then determined the effect of PTS and its main ginsenosides on human platelet aggregation. As a result, both PTS and its main ginsenosides showed significant inhibitory effect.

$\left[\mathrm{Ca}^{2+}\right]_{i}$ plays an important role in the activation and aggregation of platelets and the thrombus formation. The exogenous or endogenous activation of a membrane receptor with thrombin, collagen or ADP leads to the influx of $\mathrm{Ca}^{2+}$ into the platelets $[20,21]$. The activation of thrombin receptors PAR1 and PAR4 or a
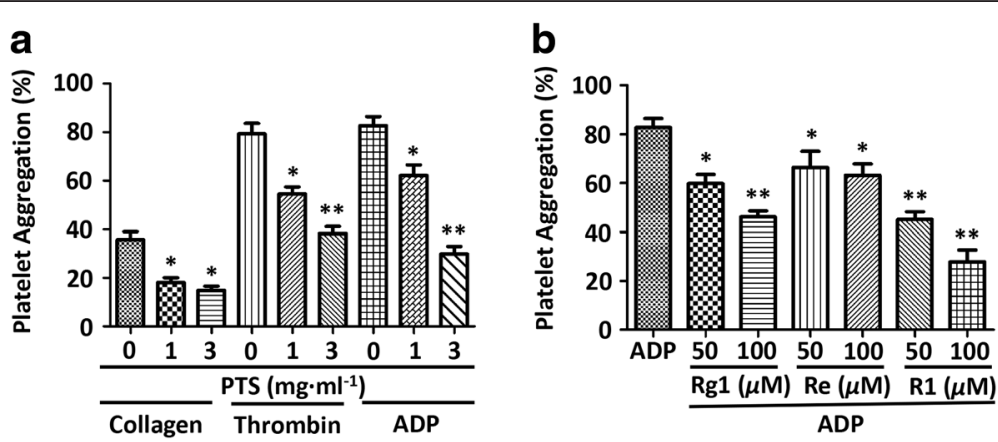

Fig. 3 Inhibitory effect of PTS and its main ginsenosides on human platelet aggregation. a Human platelets $\left(4 \times 10^{8}\right.$ cells $\left.\cdot \mathrm{ml}^{-1}\right)$ were pre-incubated with or without PTS and then stimulated with collagen $\left(2.5 \mu \mathrm{g} \cdot \mathrm{ml}^{-1}\right)$, thrombin $\left(0.1 \mathrm{U} \cdot \mathrm{ml}^{-1}\right)$ or ADP $(10 \mu \mathrm{M})$. The platelet aggregation rate was determined. b Human platelets $\left(4 \times 10^{8} \mathrm{cells} \cdot \mathrm{ml}^{-1}\right)$ were pre-incubated with or without $\mathrm{Rg} 1, \mathrm{Re}, \mathrm{R} 1$, and then stimulated with ADP $(10 \mu \mathrm{M})$. The platelet aggregation rate was determined. Bar graphs show mean \pm SD of at least 3 independent experiments performed. ${ }^{*} p<0.05,{ }^{* *} p<0.01$ vs. agonist activated control 


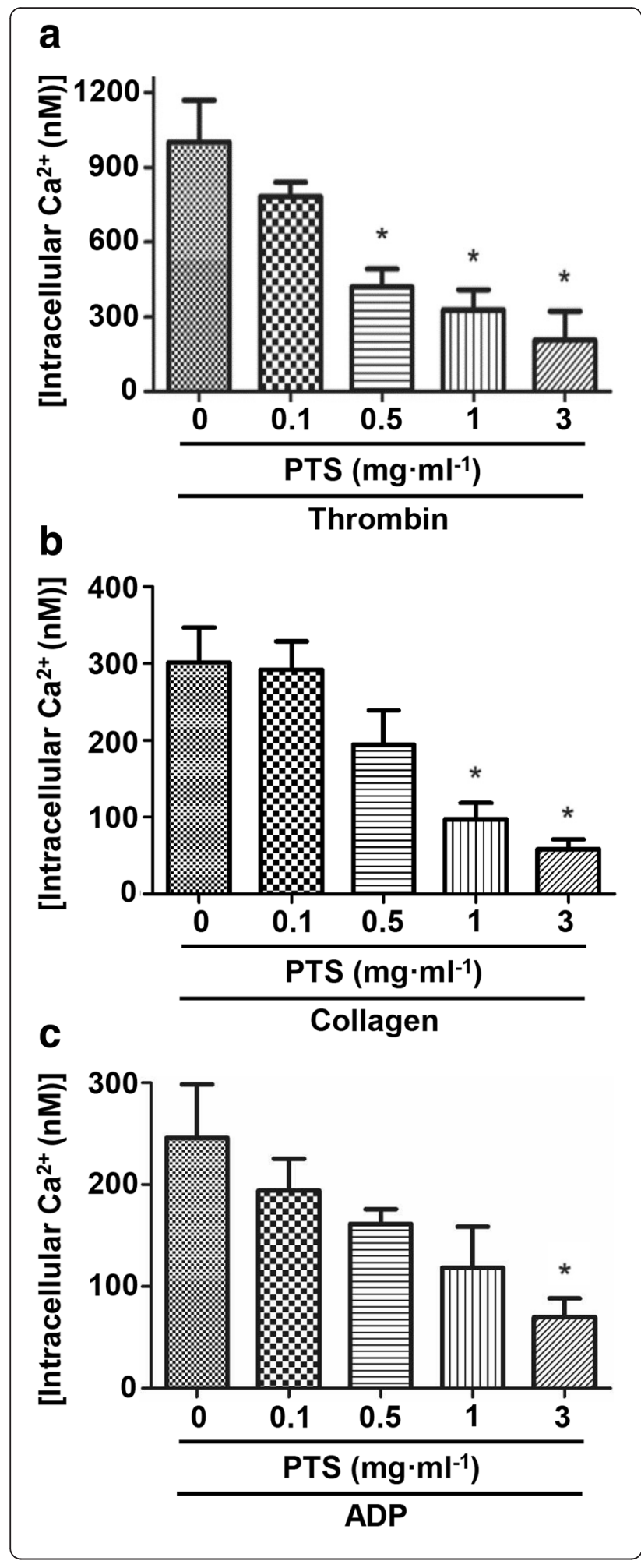

Fig. 4 Effect of PTS on intracellular $\mathrm{Ca}^{2+}$ concentration $\left(\left[\mathrm{Ca}^{2+}\right] i\right)$ in thrombin, collagen or ADP activated platelets. Platelets were loaded with Fura-2/AM as described in 'Materials and Methods Section'. The platelets $\left(4 \times 10^{8}\right.$ cells $\left.\cdot \mathrm{ml}^{-1}\right)$ were pre-incubated with or without a PTS and then the platelets were stimulated with thrombin $(0.1 \mathrm{U} / \mathrm{ml})$ (a), collagen $\left(2.5 \mu \mathrm{g} \cdot \mathrm{ml}^{-1}\right)(\mathbf{b})$ or $\mathrm{ADP}(10 \mu \mathrm{M})(\mathbf{c})$ for $5 \mathrm{~min}$, respectively. $\left[\mathrm{Ca}^{2+}\right]$ i levels were determined as described in 'Materials and Methods Section'. Bar graphs show mean \pm SD of at least 3 independent experiments performed. ${ }^{*} p<0.05$ vs. agonist activated control

P2Y ADP receptor, which belong to the Gq proteincoupled receptors, leads to the activation of phospholipase (PLC)- $\beta$. Additionally, collagen binds to glycoprotein VI on the platelet surface leading to the increase of PLC activity by phosphorylating PLC $\gamma-2$ on a tyrosine residue. Then, these receptors stimulate the release of inositol trisphosphate (IP3) from phosphatidylinositol bisphosphate (PIP2). Finally, the calcium mobilization is resulted by the binding of IP3 to type 2 IP3 receptors in the secretory granules of human platelets $[14,22,23]$. To find out the possible signaling pathway involved in the downstream of membrane receptors, we determined the effect of PTS on the intracellular calcium mobilization. In our study, all the three agonists thrombin, collagen and ADP stimulate the $\left[\mathrm{Ca}^{2+}\right]_{i}$. While pre-treatment with PTS, the $\left[\mathrm{Ca}^{2+}\right]_{i}$ in all these agonists-activated platelets remarkably reduced, suggesting that inhibition of calcium mobilization may be one of the common signaling pathways responsible for the inhibitory effect of PTS against platelet aggregation stimulated by these three different agonists.

MAPKs including ERK2, JNK1 and p38 are present in platelets and activated by various agonists [16, 24]. Our results demonstrated that PTS significantly suppressed the activation of both ERK2 and p38 induced by thrombin, collagen or ADP via reducing the expression level of p-ERK2 and p-p38. However, PTS showed no statistically significant influence on p-JNK1 (data not shown). It's reported that ERK2 and p38 have complementary effects in the control of platelet adhesion to collagen. In static adhesion condition, p38 was involved in platelet adhesion and spreading. In blood flow condition, p38 activation is required for platelet adhesion at low collagen coverage densities, while ERK2 activation is necessary for platelet adhesion at higher collagen coverage densities [16]. Therefore, suppression of ERK2 and p38 activation may be partially as a common signaling pathway responsible for the inhibitory effect of PTS on platelet aggregation in our study.

\section{Conclusion}

In summary, we have investigated the potential effect of PTS on platelet aggregation and explored the underlying 


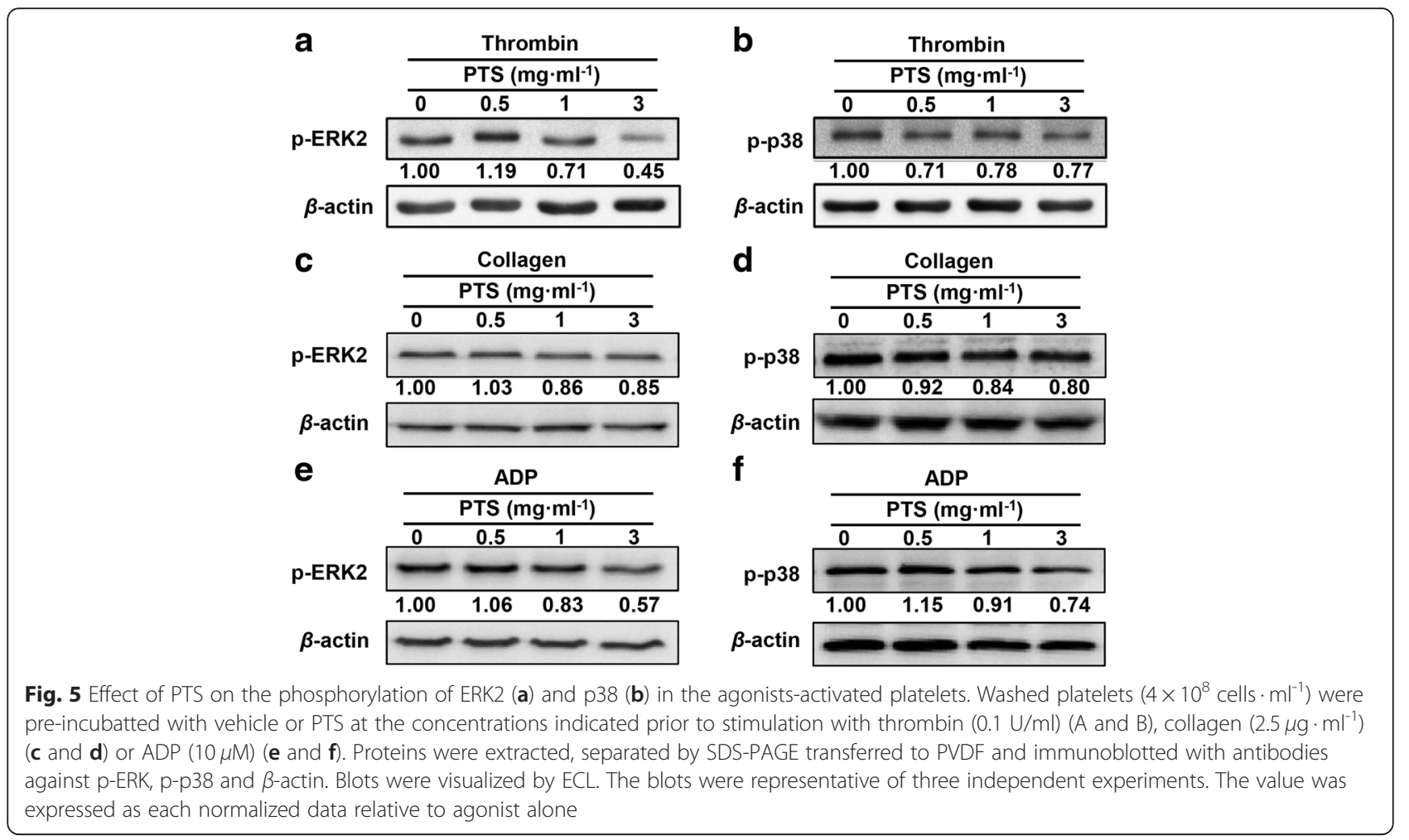

mechanisms in this study. PTS exhibited anti-platelet activity against stimulation of different agonists, including collagen, thrombin and ADP. The three major ginsenosides used alone also showed anti-platelet activity, whereas their combination didn't improve the effect synergistically. Further mechanism study revealed that PTS significantly inhibited intracellular calcium mobilization induced by the three different agonists. Moreover, PTS also inhibited the phosphorylation of ERK2 and p38 induced by all the three agonists. Collectively, our study showed PTS has anti-platelet activity and inhibition of intracellular calcium mobilization and pERK2/p-p38 may, in part, be as the common signaling pathways responsible for this effect. The anti-platelet activity of PTS may be implicated in its beneficial effect on the prevention and treatment of ischemic stroke.

\footnotetext{
Abbreviations

$A D P$, adenosine diphosphate; $B S A$, bovine serum albumin; $E C L$, enhanced chemiluminescence; EGTA, ethylene glycol tetraacetic acid; $F_{\text {max }}$ the fluorescence intensity levels at very high $\mathrm{Ca}^{2+}$ concentrations; $F_{\min }$, the fluorescence intensity levels at very low $\mathrm{Ca}^{2+}$ concentrations; GPCR, G-protein coupled seven transmembrane receptor; HEPES, 4-(2-hydroxyethyl)-1-piperazineethanesulfonic acid; HRP, horseradish peroxidase; HSP70, heat shock protein 70; IP3, inositol trisphosphate; Nrf2, nuclear factor (erythroid-derived 2)-like 2; OD, optical density; PAR, platelet aggregation rate; PIP2, phosphatidylinositol bisphosphate; PRP, platelet-rich plasma; PTS, panaxatriol saponin; PVDF, polyvinylidene difluoride; R1, notoginsenoside R1; Re, ginsenoside Re; Rg1, ginsenoside Rg1; SDS, sodium dodecyl sulfate
}

\section{Acknowledgments}

This work was supported by the NSFC Projects (No. 81373903; No. 81202946), a Doctoral Fund Program Grant (swu11107) from the Southwest University, the Key Project of Fundamental Research Fund for the Central Universities (XDJK2016B040), a Cooperative Research Program Grant (41004013) from Chengdu University of Traditional Chinese Medicine and the Chongqing Project of Science and technology talent cultivation (cstc2013kjrc-qnrc1002).

Availability of data and materials

This information is not relevant.

\section{Authors' contributions}

$H Q, Y L H, F W, W W Z, C J W$ and LL contributed to the study design, analysis, and interpretation of data. CJW and LL conceived of the study. $H Q, Y L H, F W$, WWZ, HRY, YY, GJD and LW performed the experiments. HQ and YLH drafted the manuscript. CJW and LL carried out the revision and provided important suggestions. All authors approved the final manuscript.

\section{Competing interests}

The authors declare that they have no competing interests.

\section{Consent for publication}

This information is not relevant.

Ethics approval and consent to participate

The animal experiments of this study were approved by the Committee on Animal Care at the Southwest University. Human peripheral blood was collected from healthy human donors after obtaining the informed consent under a Chengdu University of Traditional Chinese Medicine Internal Review Board-approved protocol.

\section{Author details}

${ }^{1}$ College of Pharmaceutical Sciences, Southwest University, 2 Tiansheng Road, Beibei District, Chongqing 400716, China. ${ }^{2}$ Affiliated Hospital of 
Chengdu University of Traditional Chinese Medicine, Chengdu 610075, Sichuan, China. ${ }^{3}$ Huasun Group Co., Ltd., Chengdu 610072, Sichuan, China. ${ }^{4}$ College of Pharmacy, Chengdu University of Traditional Chinese Medicine, Chengdu 611137, Sichuan, China.

\section{Received: 28 January 2016 Accepted: 3 June 2016}

\section{Published online: 08 June 2016}

\section{References}

1. Mustard JF, Packham MA. Factors influencing platelet function: adhesion, release, and aggregation. Pharmacol Rev. 1970;22(2):97-187.

2. Fuster V, Badimon L, Cohen M, Ambrose JA, Badimon JJ, Chesebro J. Insights into the pathogenesis of acute ischemic syndromes. Circulation. 1988;77(6):1213-20.

3. Wu KK, Hoak JC. Increased platelet aggregates in patients with transient ischemic attacks. Stroke. 1975;6(5):521-4

4. Yao XH, Li XJ. Protective effects and its mechanism of panaxatriol saponins isolated from Panax notoginseng on cerebral ischemia. Zhongguo Zhong Yao Za Zhi. 2002;27(5):371-3.

5. Huang $Y, Y u$ J, Wan F, Zhang W, Yang H, Wang L, et al. Panaxatriol saponins attenuated oxygen-glucose deprivation injury in PC12 cells via activation of PI3K/Akt and Nrf2 signaling pathway. Oxid Med Cell Longev. 2014;2014: 978034. doi:10.1155/2014/978034

6. Endale M, Lee WM, Kamruzzaman SM, Kim SD, Park JY, Park MH, et al. Ginsenoside-Rp1 inhibits platelet activation and thrombus formation via impaired glycoprotein VI signalling pathway, tyrosine phosphorylation and MAPK activation. Br J Pharmacol. 2012;167(1):109-27. doi:10.1111/j.14765381.2012.01967.x

7. Lee WM, Kim SD, Park MH, Cho JY, Park HJ, Seo GS, et al. Inhibitory mechanisms of dihydroginsenoside $\mathrm{Rg} 3$ in platelet aggregation: critical roles of ERK2 and CAMP. J Pharm Pharmacol. 2008;60(11):1531-6. doi:10.1211/.jpp/ 60.11.0015.

8. Liu R, Xing D, Lu H, Wu H, Du L. Pharmacokinetics of puerarin and ginsenoside $\mathrm{Rg} 1$ of CBN injection and the relation with platelet aggregation in rats. Am J Chin Med. 2006;34(6):1037-45. doi:10.1142/s0192415x06004508.

9. Wang J, Huang ZG, Cao H, Wang YT, Hui P, Hoo C, et al. Screening of antiplatelet aggregation agents from Panax notoginseng using human platelet extraction and HPLC-DAD-ESI-MS/MS. J Sep Sci. 2008;31(6-7):1173-80. doi: 10.1002/jssc.200700507.

10. Born GV. Aggregation of blood platelets by adenosine diphosphate and its reversal. Nature. 1962;194:927-9.

11. Schaeffer J, Blaustein MP. Platelet free calcium concentrations measured with fura- 2 are influenced by the transmembrane sodium gradient. Cell Calcium. 1989;10(2):101-13.

12. Qi H, Han Y, Rong J. Potential roles of PI3K/Akt and Nrf2-Keap1 pathways in regulating hormesis of Z-ligustilide in PC12 cells against oxygen and glucose deprivation. Neuropharmacology. 2012;62(4):1659-70. doi:10.1016/j. neuropharm.2011.11.012.

13. Nesbitt WS, Giuliano S, Kulkarni S, Dopheide SM, Harper IS, Jackson SP. Intercellular calcium communication regulates platelet aggregation and thrombus growth. J Cell Biol. 2003;160(7):1151-61. doi:10.1083/jcb. 200207119.

14. Kim SD, Lee IK, Lee WM, Cho JY, Park HJ, Oh JW, et al. The mechanism of anti-platelet activity of davallialactone: Involvement of intracellular calcium ions, extracellular signal-regulated kinase 2 and p38 mitogen-activated protein kinase. Eur J Pharmacol. 2008;584(2-3):361-7. doi:10.1016/j.ejphar. 2008.02.008

15. Toth-Zsamboki E, Oury C, Cornelissen H, De Vos R, Vermylen J, Hoylaerts MF. P2X1-mediated ERK2 activation amplifies the collagen-induced platelet secretion by enhancing myosin light chain kinase activation. J Biol Chem. 2003;278(47):46661-7. doi:10.1074/jbc.M308452200.

16. Mazharian A, Roger S, Maurice P, Berrou E, Popoff MR, Hoylaerts MF, et al. Differential Involvement of ERK2 and p38 in platelet adhesion to collagen. J Biol Chem. 2005:280(28):26002-10. doi:10.1074/jbc.M414083200.

17. Kuijpers MJ, Schulte V, Bergmeier W, Lindhout T, Brakebusch C, Offermanns S, et al. Complementary roles of glycoprotein $\mathrm{VI}$ and alpha2beta1 integrin in collagen-induced thrombus formation in flowing whole blood ex vivo. FASEB J. 2003;17(6):685-7. doi:10.1096/fj.02-0381fje.

18. Leon C, Alex M, Klocke A, Morgenstern E, Moosbauer C, Eckly A, et al. Platelet ADP receptors contribute to the initiation of intravascular coagulation. Blood. 2004;103(2):594-600. doi:10.1182/blood-2003-05-1385.
19. Rivera J, Lozano ML, Navarro-Nunez L, Vicente V. Platelet receptors and signaling in the dynamics of thrombus formation. Haematologica. 2009; 94(5):700-11. doi:10.3324/haematol.2008.003178.

20. Holmsen $\mathrm{H}$. Significance of testing platelet functions in vitro. Eur J Clin Invest. 1994;24 Suppl 1:3-8

21. Rink TJ, Sage SO. Calcium signaling in human platelets. Annu Rev Physiol. 1990:52:431-49. doi:10.1146/annurev.ph.52.030190.002243.

22. Daniel JL, Dangelmaier CA, Selak M, Smith JB. ADP stimulates IP3 formation in human platelets. FEBS Lett. 1986;206(2):299-303.

23. Smith JB, Selak MA, Dangelmaier C, Daniel JL. Cytosolic calcium as a second messenger for collagen-induced platelet responses. Biochem J. 1992;288(Pt 3):925-9.

24. Mazharian A, Roger S, Berrou E, Adam F, Kauskot A, Nurden P, et al. Protease-activating receptor-4 induces full platelet spreading on a fibrinogen matrix: involvement of ERK2 and p38 and Ca2+ mobilization. J Biol Chem. 2007;282(8):5478-87. doi:10.1074/jbc.M609881200.

\section{Submit your next manuscript to BioMed Central and we will help you at every step:}

- We accept pre-submission inquiries

- Our selector tool helps you to find the most relevant journal

- We provide round the clock customer support

- Convenient online submission

- Thorough peer review

- Inclusion in PubMed and all major indexing services

- Maximum visibility for your research

Submit your manuscript at www.biomedcentral.com/submit
Biomed Central 